\title{
Chronic Paronychia of Great Toe Treated with Excision of Nail Plate along with Surrounding Tissue and Split Thickness Skin Graft: An Observational Prospective Study
}

\author{
Radharaman Panda10 \\ ${ }^{1}$ Department of General Surgery, Bhima Bhoi Medical College and \\ Hospital (Government Medical College \& Hospital), Balangir, Odisha, \\ India \\ Int J Recent Surg Med Sci 2022;8:78-83.
}

Address for correspondence Radharaman Panda, MS, Department of General Surgery, Bhima Bhoi Medical College and Hospital (Government Medical College \& Hospital), Quarter no. 4R/203, Bhima Bhoi Medical College Campus, Balangir, Odisha 767002, India (e-mail: drradharaman@yahoo.co.in).

\begin{abstract}
\section{Keywords}

- chronic paronychia

- great toe

- excision and skin graft

Paronychia is an inflammatory condition of alongside of nail of toe or finger. It is seen commonly in housewives and housemaids. Paronychia may be acute or chronic. Majority of patients with acute paronychia respond well to nonsurgical treatment. Patients with chronic paronychia of great toe do not respond to nonsurgical treatment. Patients suffer from chronic pain in finger or toe. Many treatment methods are available for chronic paronychia of great toe. All have merits, demerits, and different outcomes. This study is conducted to find out the outcome of a modified surgical technique in chronic paronychia of great toe of patients. This is a method adopted with a little modification of existing method.

This study was conducted among 50 patients of chronic paronychia of great toe, who were between 15 to 55 years of age, from December 2019 to December 2020. These patients were operated and kept on follow-up for 1 year and observed for different outcomes likes skin graft take off, complete wound healing of operated area, relief from chronic pain of great toe, acceptance of cosmetic appearance, and recurrence of disease. Clinical data was recorded in case record form by examining the patient, asking questions to them, and conducting descriptive analysis. Results in terms of skin graft take off, complete wound healing of operated area, relief from chronic pain of great toe, acceptance of cosmetic appearance, and recurrence of disease were assessed during follow-up period. Postoperative result showed that $98 \%$ of patients had complete wound healing and complete graft take up, acceptance of cosmetic appearance was $94 \%$, recurrence was $2 \%$, and $90 \%$ were relieved from chronic pain of disease great toe. It was concluded that this was a better method for treatment of chronic paronychia of great toe.
\end{abstract}

DOI https://doi.org/ $10.1055 / \mathrm{s}-0041-1739374$ ISSN 2455-7420.

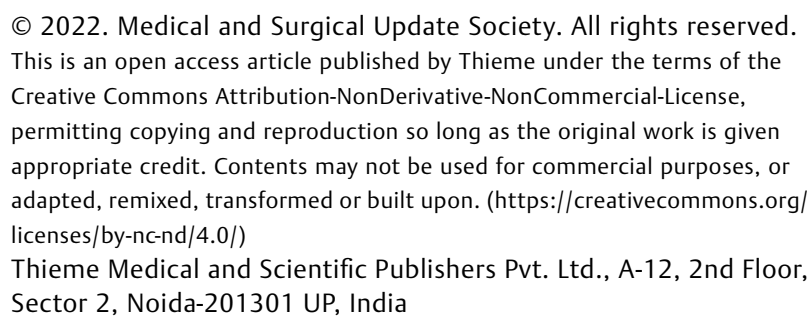




\section{Introduction}

Paronychia is an inflammation of nail fold of finger or toe. It presents with pain, swelling, redness, and tenderness surrounding the nail. Cause may be infective, traumatic, exposure to chemical irritant, or systemic drug-induced. ${ }^{1-7}$ Patients with short duration present with acute paronychia, and when duration of paronychia is more than 6 weeks, it proceeds to chronic stage of inflammation. It is found in housewives and housemaids and also male labor class, with prolong repeated exposure to water and irritant chemical and other pollutants. Patients who are unable to take care of their own toe area, which is neglected, suffer chronic paronychia of great toe. Chronic paronychia is also found in hairdressers ${ }^{8}$ and food handlers. ${ }^{9}$ Patients frequently visit hospital for long duration with frequent topical application of steroid, antifungal and antibacterial with oral doses of antibiotic and antifungal. Patients come to hospital with chronic pain and deformity of tissue surrounding the nail.

Paronychia may or may not be associated with ingrowing toenail. Acute paronychia without ingrowing toenail respond well to medical treatment like topical antibacterial, oral antibiotic, and hot compression to inflamed area. If it presents with abscess, then surgical (incision and drainage) treatment is required. Usually, paronychia with ingrowing toenail with recurrent acute episodes not responding to standard medical and surgical treatment of prolong duration becomes chronic paronychia. Chronic paronychia never responds to medical treatment, as it needs surgical treatment.

Treatment for complete cure of chronic paronychia of great toe is challenging to surgeon. In our institute, patients come with recurrence of chronic paronychia great toe, having previously multiple surgery like excision of nail fold or excision of nail surrounding to nailfold. Patients experience lot of pain, discomfort, and morbidity, which hinders the work activity.

Different treatment methods are available for treatment of chronic paronychia such as en bloc excision of nailfold, ${ }^{10}$ square flap technique ${ }^{11}$ eponychial marsupialization, ${ }^{12}$ Swiss roll technique ${ }^{13}$ laser treatment, ${ }^{14}$ and silver nitrate chemical cauterization. ${ }^{15}$ All these methods have some merits, demerits, and different outcomes. This study was conducted to find out the outcome of a modified surgical technique in chronic paronychia of great toe of patients. In the surgical method in this study, partial excision of nail plate, excision of diseased surrounding tissue, and splitthickness skin graft (STSG) was done.

The aim of this study was to find out the different outcomes as a result of methods of treatment: 1 . skin graft takeoff; 2. complete wound healing of operated area within 2 weeks; 3 . relief from chronic pain of great toe; 4 . acceptance of cosmetic appearance; and 5. recurrence of disease.

\section{Patients and Methods}

An observational prospective study was performed at the Department of General Surgery at Bhima Bhoi, Government
Medical College and Hospital, Balangir, which is a tertiary care referral teaching hospital of western Odisha. Before conducting the study, Institutional Ethical Committee approval was taken. Consecutive cases of chronic paronychia of great toe of those between 15 to 55 years of age and across all sexes were included. In between December 2019 to December 2020, 50 patients attended the Department of Surgery. All cases of chronic paronychia of great toe of foot were enrolled during the study period. These patients presented with pain, swelling, discomfort, deformity of nail and nail fold, and chronic discharge from nail fold. Each patient's history was taken, examined properly, and evaluated. Diseases like diabetes mellitus, hypertension, tuberculosis, chronic obstructive pulmonary diseases (COPD), any autoimmune disease, vascular diseases, central nervous system (CNS) diseases, serious myocardial problem, and chronic osteomyelitis of great toe phalanx bone were excluded. All 50 patients were free of the abovementioned diseases. Patients were categorized as per age, sex, and different sites of occurrence. X-ray of operated foot was done in all patients. Patients with osteomyelitis in phalanx bone of great toe were excluded from study. All patients preoperatively had normal hemogram, liver function test, renal function tests, normal chest X-ray, normal X-ray foot, and normal electrocardiogram. Counselling of all 50 patients were done about the risks and complications of surgery (peroperative and postoperative) like severe bleeding, loss of skin graft, permanent cosmetic deformity, keloid formation and severe infection of operated area, chronic pain of operated area, and complication of anesthesia. All patients agreed for surgery under local or spinal anesthesia. Written consent was taken from patient for excision of nail plate along with surrounding tissue of diseased great toe and STSG under local (great toe digital block) or spinal anesthesia. Part was prepared by hair shaving from knee to ankle joint. Part was cleaned with soap and water before 2 hours of surgery. Before procedure of surgery, sensitivity test of lidocaine hydrochloride was performed. Surgical procedure (excision of nail plate along with surrounding tissue of diseased great toe and STSG) was performed, patient was discharged from hospital after treatment, and follow-up done. During follow-up period, each patient was examined and asked questions, and clinical data was collected and recorded in a predesigned case record form. The data was entered in a Excel sheet, and descriptive analysis was done by using a statistical software in a personal computer.

\section{Procedure of Surgery}

Surgery was performed under local anesthesia $(5 \mathrm{~mL}$ of $2 \%$ lidocaine hydrochloride subcutaneous infiltration circumferentially at base of disease great toe) (-Fig. 1) or spinal anesthesia. Intravenous set of plastic tube was used as tourniquet, which was applied at base of great toe (-Fig. 2). Incision was given on distal phalanx of great toe, covering the lateral part of nail plate, diseased nail fold and anterior part of lateral nail fold, including approximately $1 \mathrm{~mm}$ of healthy margin (-Fig. 3). Incision was deepened till healthy soft tissue. Nail plate along with surrounding nail 


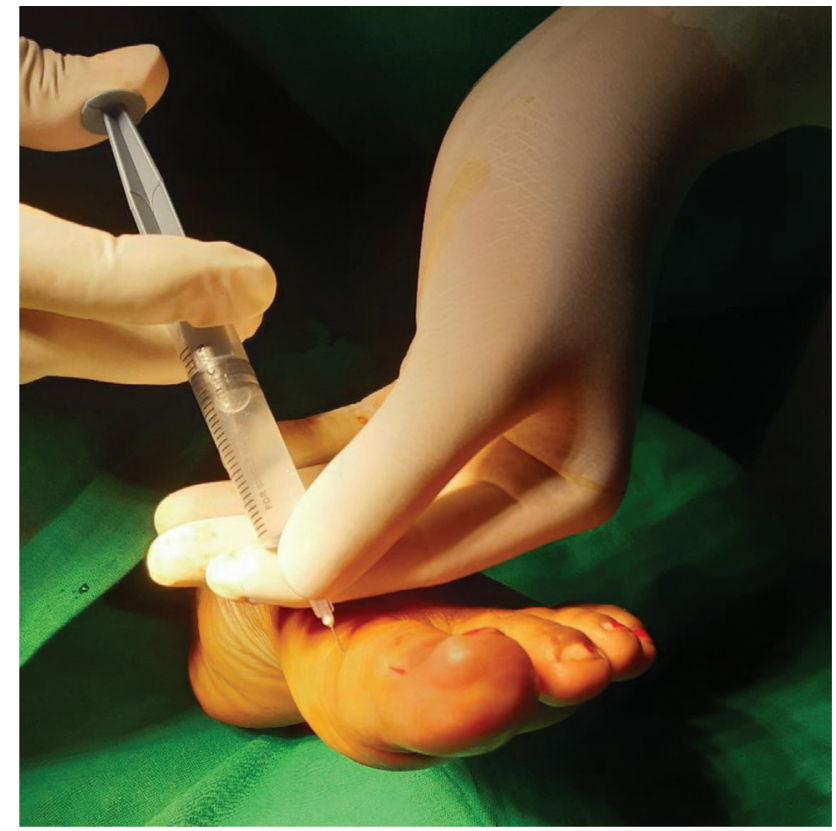

Fig. 1 Subcutaneous infiltration of $2 \%$ lidocaine at base of disease great toe.

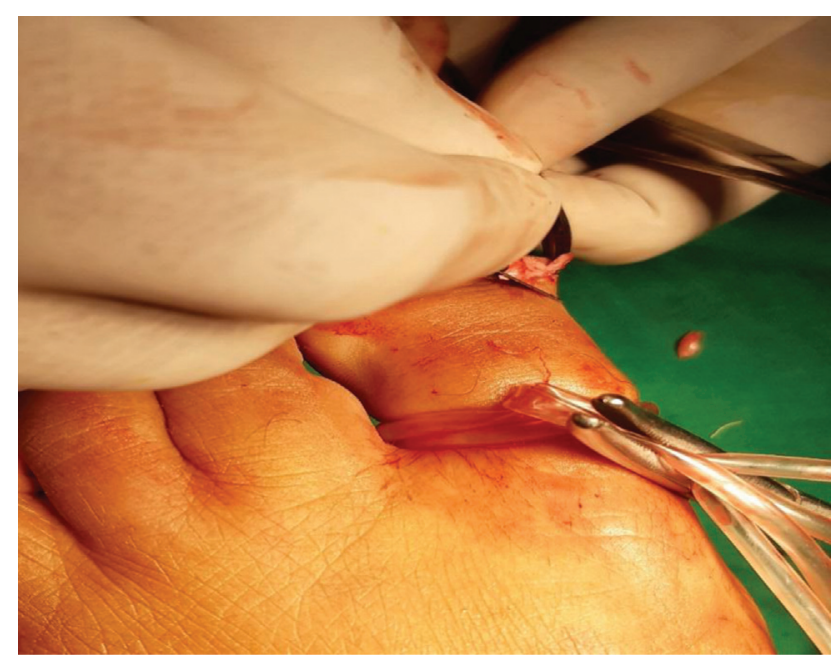

Fig. 2 Tourniquet was applied at base of great toe.

fold tissue was excised (-Fig. 4). After excision, on touching the depth of raw area, it was soft as compared with excised disease tissue. Raw area was irrigated with normal saline. About $2 \mathrm{~mL}$ of lidocaine was injected subcutaneously at donor area of leg or thigh of same side of disease toe (as per consent given by patient for donor area for STSG), and required amount of STSG was measured same as raw area of great toe. Skin graft was taken from leg of same side (-Fig.5).

Donor area was covered with sterile dressing and bandage. STSG was washed with normal saline. Skin graft was applied on raw area of great toe and fixed with 3-0 curve cutting silk suture on margin of raw area (-Fig. 6). On the graft, paraffin tulle was applied, sterile cotton soaked with $5 \%$ povidone iodine solution applied over the tulle area, and tie over bolus dressing done. Tourniquet was removed. Again, bulky dressing was done, great toe was immobilized with

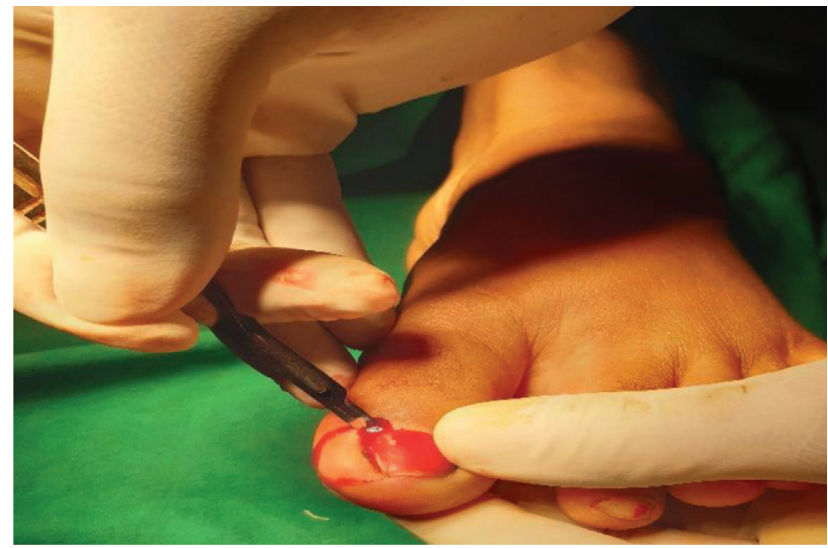

Fig. 3 Incision was given on distal phalanx of great toe covering to lateral part of nail plate, diseased nail fold, and anterior part of lateral nail fold.

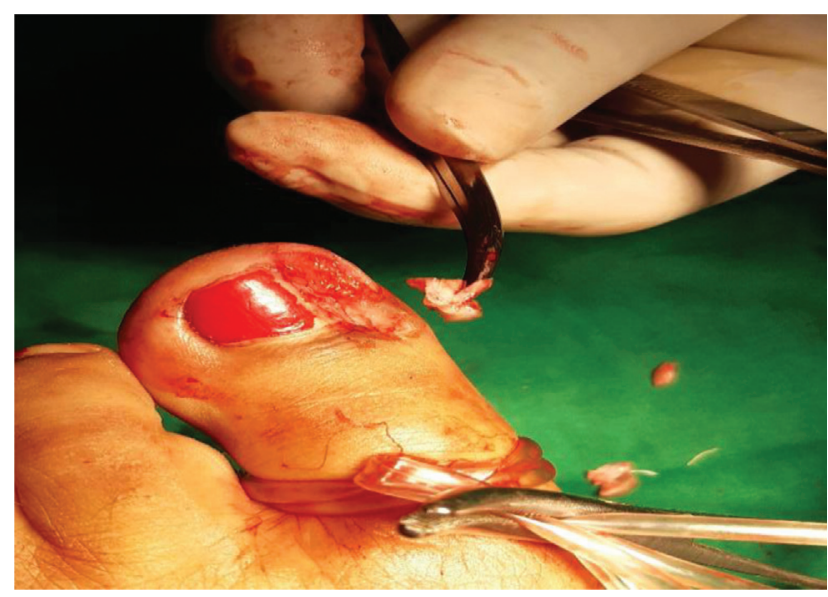

Fig. 4 Nail plate along with surrounding nail fold tissue was excised.

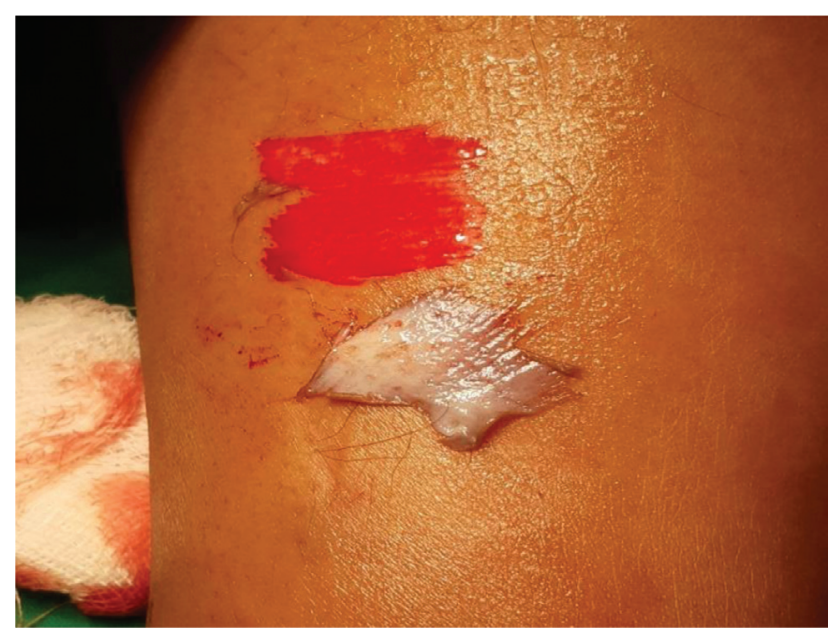

Fig. 5 Split thickness skin graft (STSG) was measured same as raw area of great toe. Skin graft was taken from leg of same side.

plaster of Paris posterior slab below knee, and pressure bandage was applied on great toe and foot (-Fig. 7). Postoperatively, patient was kept for 2 hours in indoor and after that point was discharged, and advised to take oral antibiotics for 7 days, no walking on operated foot for 7 days and 


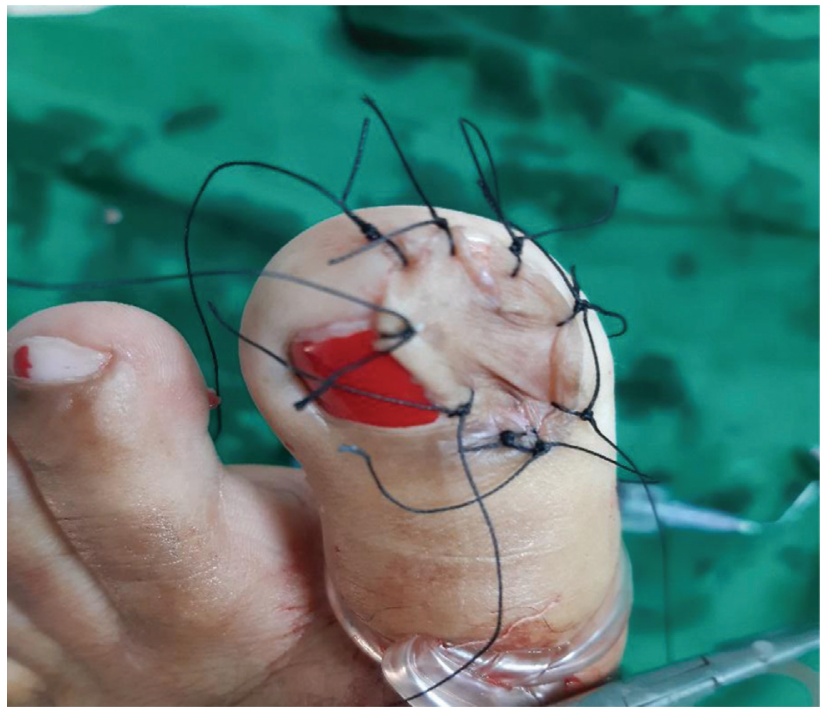

Fig. 6 Skin graft was applied on raw area of great toe and fixed with 3-0 silk suture on margin of raw area.

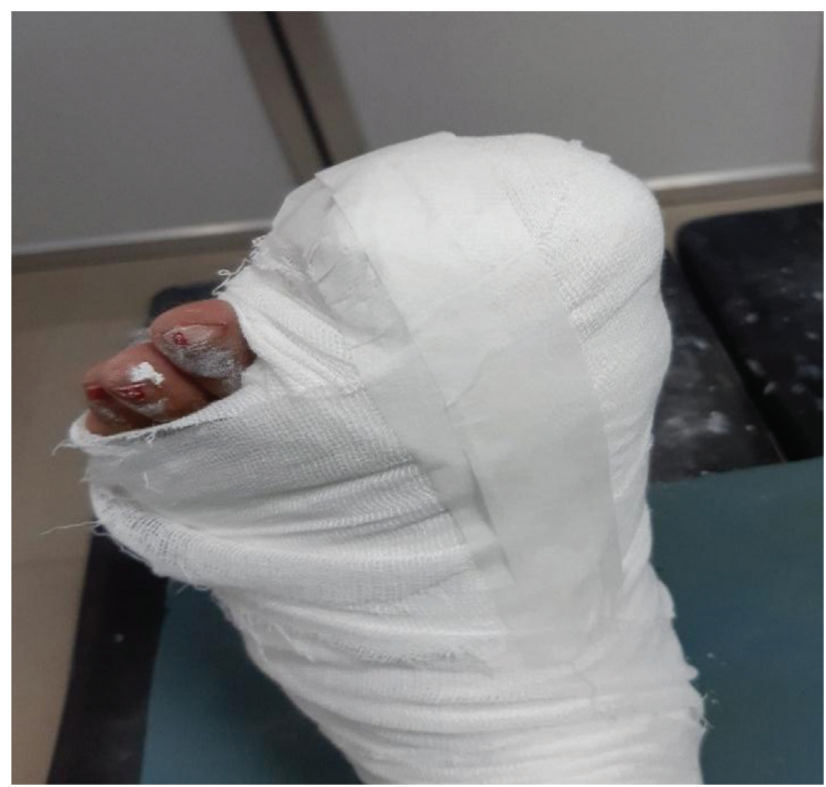

Fig. 7 Dressing was done, and great toe was immobilized with plaster of Paris posterior slab below knee.

elevation of operated foot during sleep for 7 days. Patient was called for stitches removal on 10th postoperative day. Stiches was removed on 10th postoperative day (-Fig. 8) and assessed for whether skin graft was taken completely or partially after that area was dressed. Bandage of donor area was removed and assessed after that patient was advised for application of paraffin on donor area and operated great toe for 2 to 3 months. On 2nd week of follow-up, complete healing of operated area was found (-Fig. 9). Patient was called for follow-up every 2 weeks for 2 months, then monthly for 2 months, and finally every 4 th month. During postoperative follow-up period, we assessed for skin graft take up, duration of wound healing, pain relief, cosmetic acceptance of operated toe, and recurrence of disease. All

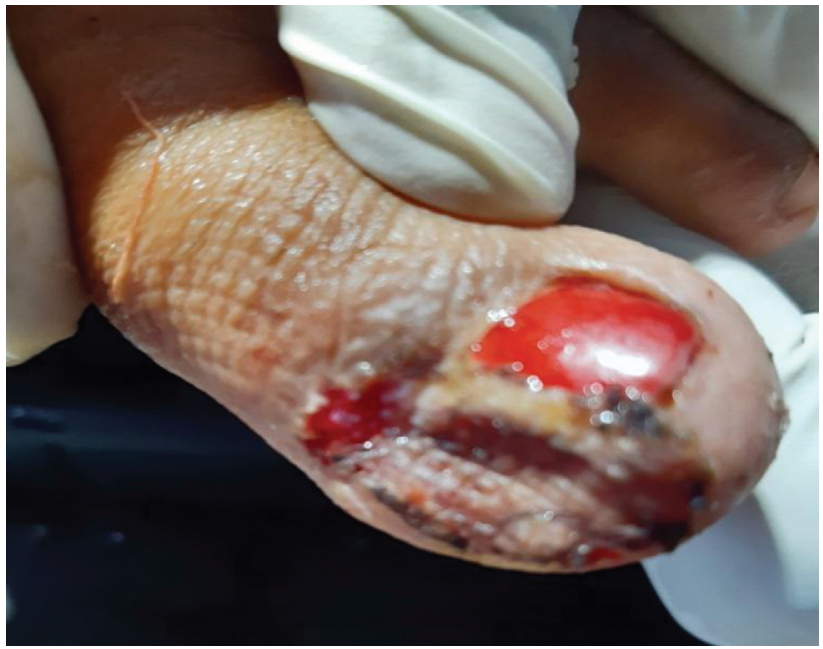

Fig. 8 On 10th postoperative skin graft was taken completely.

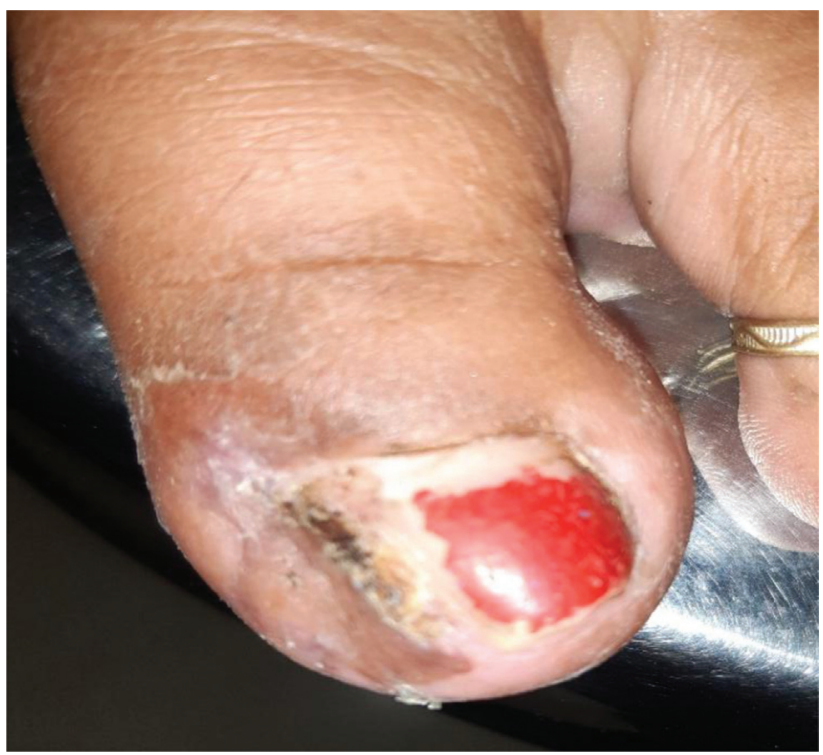

Fig. 9 On 2nd week of follow-up complete healing of operated area.

data was collected and recorded during postoperative follow-up period.

\section{Results}

\section{Gender Distribution}

In our study, it was found that out of 50 patients suffering from chronic paronychia of great toe, gender distribution was $56 \%(n=28)$ are women and $44 \% n=22)$ are men (-Table 1).

Table 1 Distribution of gender of chronic paronychia of great toe patients

\begin{tabular}{|l|l|l|}
\hline Gender & No. of patients $(\boldsymbol{n})$ & Percentage (\%) \\
\hline Male & 22 & 44 \\
\hline Female & 28 & 56 \\
\hline
\end{tabular}


Table 2 Distribution of age group of patients with chronic paronychia of great toe

\begin{tabular}{|l|l|l|}
\hline $\begin{array}{l}\text { Age group } \\
\text { in years }\end{array}$ & No. of patients $(\boldsymbol{n})$ & Percentage (\%) \\
\hline $15-25$ & 18 & 36 \\
\hline $26-35$ & 11 & 22 \\
\hline $36-45$ & 13 & 26 \\
\hline $46-55$ & 8 & 16 \\
\hline
\end{tabular}

Table 3 Side distribution of chronic paronychia of great toe patients

\begin{tabular}{|l|l|l|}
\hline Side & Number of patients $(\boldsymbol{n})$ & Percentage (\%) \\
\hline Left side & 30 & 60 \\
\hline Right side & 16 & 32 \\
\hline Bilateral & 4 & 8 \\
\hline
\end{tabular}

\section{Age Group Distribution}

In this study, out of 50 patients who were suffering from chronic paronychia, age group distribution was $36 \%(n=18)$ in age between 15 to 25 years, $22 \%(n=11)$ in age between 26 to 35 years, $26 \%(n=13)$ in age between 36 to 45 years, and $16 \%(n=08)$ between age 46 to 55 years ( - Table 2 ).

\section{Side Distribution}

Out of the total patients ( $n=50)$, side distribution of chronic paronychia of great toe was $60 \%(n=30)$ on left side, $32 \%$ $(n=16)$ on right side, and $8 \%(n=04)$ on bilateral involvement (-Table 3).

\section{Outcomes}

In follow-up period, patients had different outcomes in terms of complete skin graft take up on 10th postoperative day (98\%; $n=49)$, partial skin graft take up (2\%;n=2), and approximately $94 \%(n=47)$ accepted the operated area. Relief from chronic pain of disease great toe $(90 \% ; n=45)$ and complete healing of operated area of great toe and donor area within 2 weeks (98\%; $n=2)$ (-Table 4).

\section{Discussion}

The nail plate is embedded by the proximal and lateral folds. ${ }^{16}$ The lateral and proximal nail folds form a distally open frame for the growing nail. ${ }^{17}$ Proximal nail fold is a wedge-shaped fold of skin lying on the dorsum of finger and toes, which covers approximately one-fourth of the total nail length. The skin on either side of the nail is an extension of the proximal nail fold and is known as the lateral nail fold. The stratum corneum of eponychium forms a thick rim of keratinous material, known as cuticle, around the margins of the proximal nail fold which along with the proximal and lateral folds provide protection against penetration of water
Table 4 Different outcomes of patients of chronic paronychia of great toe treated with excision of nail plate along with surrounding tissue and STSG

\begin{tabular}{|l|l|l|}
\hline Different outcomes & $\begin{array}{l}\text { No. of } \\
\text { patients }(\boldsymbol{n})\end{array}$ & $\begin{array}{l}\text { Percentage } \\
\text { of patient (\%) }\end{array}$ \\
\hline $\begin{array}{l}\text { Complete skin graft } \\
\text { take up }\end{array}$ & 49 & 98 \\
\hline Partial graft take up & 1 & 2 \\
\hline Cosmetic acceptance & 47 & 94 \\
\hline Relief from chronic pain & 45 & 90 \\
\hline Recurrence & 1 & 2 \\
\hline $\begin{array}{l}\text { Complete healing of } \\
\text { operated area within } \\
2 \text { weeks }\end{array}$ & 49 & 98 \\
\hline
\end{tabular}

Abbreviation: STSG, split thickness skin graft.

and toxic chemicals. ${ }^{18}$ Chronic inflammation of nail fold of great toe results from the disruption of the protective barrier between the nail and the nail fold. Chronic paronychia is a multifactorial inflammatory condition primarily caused by exposure to environmental allergens or irritants. ${ }^{19}$ Repeated several episodes of acute paronychia of great toe leads to chronicity. Chronic paronychia patients attended to our institute with duration of disease within 6 month to 3 years. On observation, it was found that longer the duration, more severe was the disease with more pain, multiple patchy scarring, multiple nodules, red tender nail fold, surrounding nail plate, swollen thick irregular nodular firm consistency with deformity. Some patients had previous history of nail fold surgery (excision of lateral nail fold) and after that suffered from recurrent paronychia. It was found that maximum number of patients (36\%) were in age group between 15 to 25 years and more females had chronic paronychia as compared with male patients.

In this study, we observed that out of 50 patients, left side of great toe is $60 \%(n=30)$, right side $32 \%(n=16)$, and $8 \%$ $(n=4)$ were bilateral great toe chronic paronychia. On follow-up of patients, it was observed and found that complete STSG taken up was $98 \%(n=49)$, partial skin graft take up $2 \%$ $(n=01)$, complete healing of wound was $98 \%(n=49)$, relief from chronic pain (as patient experienced before treatment) disease toe was $90 \%(n=45)$, cosmetic acceptance of patients was $94 \%(n=47)$, and recurrence of diseases was $2 \%(n=01)$.

About $2 \%(n=1)$ had partial skin graft take off. These patients had delayed healing, which was managed by dressing by paraffin tulle. These delayed healing patients suffered from recurrence of disease after 6 months of follow-up.

At present, throughout the world, the most common surgical treatment for chronic paronychia is en bloc excision of nail and disease nail fold or only excision of diseased nail fold. In this method of surgery, raw area was created, and healing occurring was secondary which caused scarring surrounding the toenail. Scar tissue surrounding the toenail was less vascular, with very thin epithelium. As the scar tissue is usually dry, it is labile to injury and so there are 
chances of recurrence of chronic paronychia. In our study, we performed partial excision of nail plate along with surrounding diseases nail fold followed by STSG of the raw area. In our surgical method of treatment, little modification as STSG was applied on secondary defect (raw area after excision). In our method, healing of wound was accelerated primarily by STSG, and patients did not require postoperative multiple close dressing of operated area. Some patients who had poor graft take up needed postoperative close dressing. Patients were comfortable postoperatively. Wound healing was excellent, and patients accepted postoperative cosmetic appearance of operated toe. All patients' donor areas healed without any donor area defect and deformity. Maximum patients got permanent relief from chronic pain of diseased toe, so their work efficacy improved. Recurrence of disease was very minimal.

\section{Conclusion}

In this study, this method of treatment of chronic paronychia of great toe was well-accepted by patients due to absence of any defect and deformity of operated area after surgery, early healing, less discomfort to operated area and permanent relief from chronic pain. Cosmetic appearance of operated area was well-accepted by patients, and recurrence of disease was very less. This surgical technique may also provide suitable treatment for recurrent chronic paronychia of great toe. So, this method of treatment is better to perform for cure of chronic paronychia of great toe.

Conflict of Interest

None declared.

\section{Reference}

1 Duhard É [Paronychia]. Presse Med 2014;43(11):1216-1222

2 Black JR. Paronychia. Clin Podiatr Med Surg 1995;12(02):183-187
3 Daniel CR III. Paronychia. Dermatol Clin 1985;3(03):461-464

4 Leggit JC. Acute and Chronic Paronychia. Am Fam Physician 2017; 96(01):44-51

5 Lomax A, Thornton J, Singh D. Toenail paronychia. Foot Ankle Surg 2016;22(04):219-223

6 Wollina U. Systemic drug-induced chronic paronychia and periungual pyogenic granuloma. Indian Dermatol Online J 2018;9 (05):293-298

7 Kwon SH, Choi JW, Hong JS, et al. Gefitinib-induced paronychia: response to autologous platelet-rich plasma. Arch Dermatol 2012; 148(12):1399-1402

8 Allouni A, Yousif A, Akhtar S. Chronic paronychia in a hairdresser. Occup Med (Lond) 2014;64(06):468-469

9 Tosti A, Guerra L, Morelli R, Bardazzi F, Fanti PA. Role of foods in the pathogenesis of chronic paronychia. J Am Acad Dermatol 1992;27(5 Pt 1):706-710

10 Grover C, Bansal S, Nanda S, Reddy BS, Kumar V. En bloc excision of proximal nail fold for treatment of chronic paronychia. Dermatol Surg 2006;32(03):393-398

11 Ferreira Vieira d'Almeida L, Papaiordanou F, Araújo Machado E, Loda G, Baran R, Nakamura R. Chronic paronychia treatment: square flap technique. J Am Acad Dermatol 2016;75(02):398-403

12 Keyser JJ, Eaton RG. Surgical cure of chronic paronychia by eponychial marsupialization. Plast Reconstr Surg 1976;58(01): 66-70

13 Pabari A, Iyer S, Khoo CT. Swiss roll technique for treatment of paronychia. Tech Hand Up Extrem Surg 2011;15(02):75-77

14 El-Komy MH, Samir N. 1064 Nd:YAG laser for the treatment of chronic paronychia: a pilot study. Lasers Med Sci 2015;30(05): $1623-1626$

15 Sato N, Yuda J, Yamauchi N, et al. [Successful treatment with silver nitrate chemical cauterization for paronychia and granulation in a patient with chronic lymphocytic leukemia undergoing ibrutinib therapy]. Rinsho Ketsueki 2021;62(01):35-41

16 de Berker D. Nail anatomy. Clin Dermatol 2013;31(05):509-515

17 Haneke E. Anatomy of the nail unit and the nail biopsy. Semin Cutan Med Surg 2015;34(02):95-100

18 Baswan S, Kasting GB, Li SK, et al. Understanding the formidable nail barrier: A review of the nail microstructure, composition and diseases. Mycoses 2017;60(05):284-295

19 Macneal P, Milroy C. Paronychia Drainage. Treasure Island (FL): StatPearls Publishing; 2020 